\title{
Spectroscopic Study of UV Transparency of Some Materials
}

\author{
Samuel S. Sackey ${ }^{1,2}$, Michael K. Vowotor ${ }^{3}$, Alfred Owusu ${ }^{3}$, Patrick Mensah-Amoah ${ }^{3}$, Ebenezer T. Tatchie ${ }^{3}$, Baah \\ Sefa-Ntiri ${ }^{3}$, Christiana O. Hood ${ }^{3} \&$ Sampson M. Atiemo ${ }^{4}$ \\ ${ }^{1}$ Laser and Fibre Optics Centre, Department of Physics, University of Cape Coast, Cape Coast, Ghana \\ ${ }^{2}$ Inst. of Atmospheric Sci. \& Climate of Italian National Research Council (ISAC-CNR), Bologna, Italy \\ ${ }^{3}$ Department of Physics, University of Cape Coast, Cape Coast, Ghana \\ ${ }^{4}$ National Nuclear Research Institute, Ghana Atomic Energy Commission, Accra \\ Correspondence: Samuel S. Sackey, Laser and Fibre Optics Centre, Department of Physics, University of Cape \\ Coast, Cape Coast, Ghana. Tel: 233-24-334-4777. E-mail: ssackey@ucc.edu.gh
}

Received: July 5, 2015 Accepted: July 23, 2015 Online Published: September 28, 2015

doi:10.5539/ep.v4n4p1 URL: http://dx.doi.org/10.5539/ep.v4n4p1

\begin{abstract}
Elevated exposure to Ultra-Violet Radiation (UVR) from the sun has led to adverse effects on human skin and foods, and therefore, the need for materials that offer resistance to Ultra-Violet (UV) penetration for protection. Some building window and non-window-materials, car-glasses, Linear Low Density Polyethylene (LLDPE) and Polyethylene Terephthalate (PET) rubber and plastic materials have been investigated to determine their transparencies and suitability for use as shields against UVR. These were studied by directly measuring scattered solar radiation through the optical window of a spectrometer and then measuring the scattered light when the window was completely covered with the material to be examined. Wavelengths of light that were not absorbed when sunlight was incident on the samples and the transmitted intensity of sunlight at each wavelength through each sample as compared to the transmitted intensity through air were determined in the UVB and UVA spectral regions. The results showed that the building window-glasses were opaque to UVB but transparent to UVA while the non-window-glasses exhibited transparency in the UVB and UVA spectral regions. The car-glass (laminated), used as windscreen, was opaque to UVB and UVA while the side-glass (non-laminated) was opaque to UVB but transparent to UVA. Perspex, sometimes used as an alternative to windscreen and side-glass in cars, exhibited transparency in UVB and UVA spectral regions. The LLDPE materials used for food storage were transparent to UVB and UVA while the PET plastic materials used for water, fruit juice and beverage storage was opaque to UVB but transparent to UVA.
\end{abstract}

Keywords: building window-glasses, elevated UV exposure, LLDPE materials, non-window-glasses, PET plastic materials, scattered solar radiation, spectrometer, UV transparency, UVA radiation, UVB radiation

\section{Introduction}

The sun indeed supports all life on our planet, but its life-giving rays also pose a threat in the form of Ultra-Violet Radiation (UVR) present between $200 \mathrm{~nm}-400 \mathrm{~nm}$. Typically, the sun's radiation has a continuous energy spectrum over a wavelength range of about $0.7 \mathrm{~nm}$ to $3000 \mathrm{~nm}$ with the portion reaching the surface of earth extending from $290 \mathrm{~nm}$ to $3000 \mathrm{~nm}$ (Reinert, Fuso, Hilfiker \& Schmidt, 1997). This covers part of the Ultra-Violet (UV), visible and Infra-Red (IR) portions of the electromagnetic spectrum as shown in Figure 1 (Modified, Wallace \& Hobbs, 1977). 


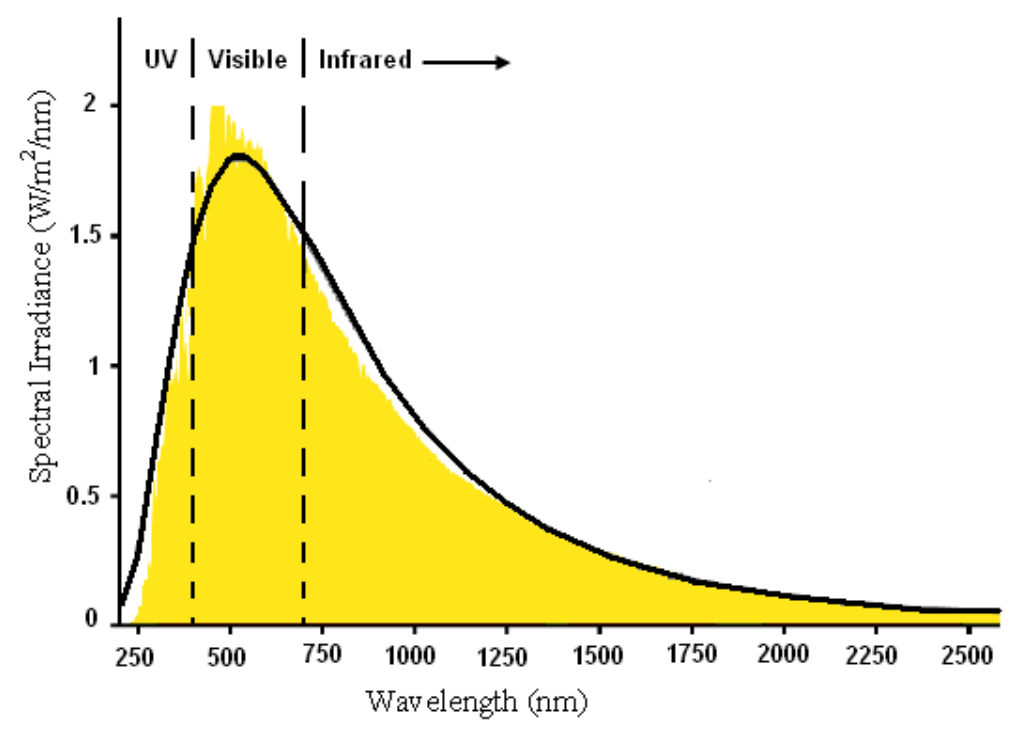

Figure 1. Spectrum of the solar radiation at the top of the atmosphere for average atmospheric conditions and an overhead sun showing the portion reaching the surface of earth (Modified, Wallace \& Hobbs, 1977)

Generally there are three subtypes of UVR: Ultra-Violet Radiation C (UVRC), Ultra-Violet Radiation B (UVRB), and Ultra-Violet Radiation A (UVRA). The ozone layer blocks $98.7 \%$ of UVR from reaching the earth, with the $1.3 \%$ that gets to the earth lying between $290 \mathrm{~nm}$ and $400 \mathrm{~nm}$. UVRC is the shortest with a wavelength range of $100 \mathrm{~nm}-290 \mathrm{~nm}$. It possesses the highest energy and greatest potential for biological damage but does not reach the earth's surface as that portion is filtered out by the ozone layer. The UVR that reaches the earth's surface therefore consists of UVRB 3.5\% and UVRA 96.5\% (Diffey, 2002). Figure 2 shows a typical profile of ozone density versus altitude (red line) and UVR as a function of altitude for UVA, UVB, and UVC. The width of the bar indicates the amount of energy as a function of altitude. The dramatic decrease in the energy of UVC is due to the strong absorption in that wavelength band by ozone. UVB is also absorbed, with a small fraction reaching the surface, while UVA is only weakly absorbed by ozone, therefore permitting a greater portion to reach the earth's surface (Newman, McGee \& Burris, 2002).

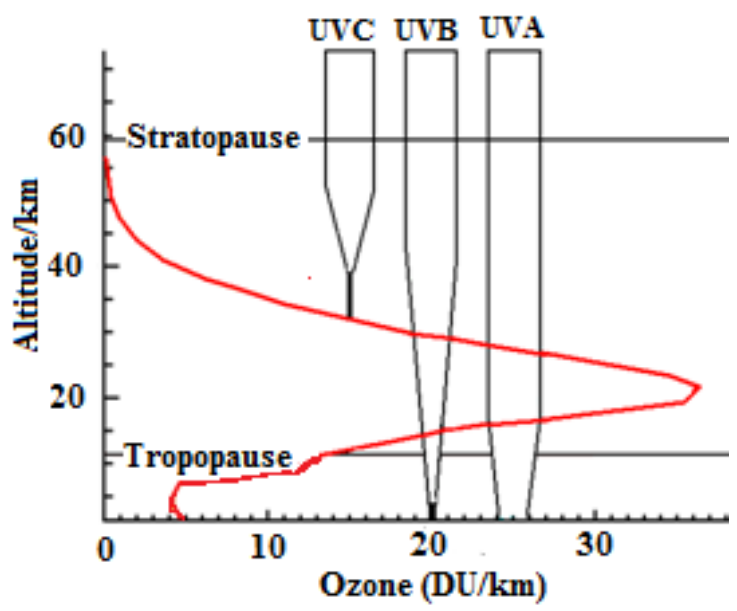

Figure 2. Typical ozone density profile (red line) and UVR as a function of altitude for UVA, UVB, and UVC.(Modified, Newman, McGee \& Burris, 2002)

UVR reaching the earth has quantum energy of the order of magnitude of organic molecule's bond energy and exhibits both positive and negative effects. Considering its negative consequences, its immense destructive effect on the human skin (Palacin, 1997) and our foods (Kolakowska, 2003) can be mentioned. The human skin, which is made up of an outer layer (epidermis), middle layer (corium) and a lower layer (cutis), is the interfacial contact 
zone with the atmosphere and serves to protect the delicate organs in the body. Unlike visible light and IR radiations that can penetrate all three layers, UVR's are completely absorbed by the epidermis and the corium, with the longest wavelength UVR's penetrating deeper than the shorter wavelengths (Achwal, 1997). UVRB has a wavelength range $290 \mathrm{~nm}-320 \mathrm{~nm}$ and penetrates a few millimeters into the skin. It causes the formation of a relatively stable pigment in the cells of the epidermis leading to acute chronic reactions and damages such as skin-reddening (erythema) or sunburn. UVRA is the longest and has a wavelength between $320 \mathrm{~nm}-400 \mathrm{~nm}$. Its presence causes a transformation of melanin precursors in the skin as it penetrates deeply into the dermis or true skin. This results in premature ageing, which is made evident in the form of loss of elasticity accompanied by lines and wrinkles, ocular damage, and skin cancer (Palacin, 1997; Almahroos \& Kurban 2004; Cummings, Tripp \& Herrmann, 1997; Sliney, 2001; Young, 1992, 2003). In the United States, one person in five will develop skin cancer at some point in their lifetime, resulting in more than one million new cases of sun-induced carcinomas being diagnosed every year (Edlich et al., 2004).

In a study conducted in 2003 on UV protection, the authors concluded that shade-structures did not effectively protect one against the dangers presented by the exposure to diffuse UVR (Turnbull \& Parisi, 2003).With the interior of automobiles, as well as any inhabited space within the vicinity of open or closed glass-windows being included in the definition of a shade-structure, the assertion therefore that staying indoors automatically shields one from the harmful effects of UVR is not wholly accurate. Current architectural designs increasingly integrate more and larger window areas with the aim of providing protection from the outside elements (the sun's rays inclusive), while providing a view and permitting visible light transmittance. Standard window-glass filters out UVRB, but transmits UVRA, visible light and IR radiation (Almutawa, Vandal, Wang \& Lim, 2013), with the fraction of UVRA that is allowed through being dependent on the make of the glass and its coating. Window-glass falls into three distinct groupings: clear, reflective, and tinted-glass.

Clear glass is transparent and permits up to $72 \%$ of UVRA to pass through while reflective and tinted glasses allow $25-50 \%$ to pass through. Reflective glass reflects light and heat through the use of metal oxide coatings that typically give the glass a mirror-like appearance while minimizing unwanted solar heat gain. Tinted-glass contains color components specifically added due to their aesthetic properties and ability to reduce unwanted solar heat transmission by absorbing $40-50 \%$ of incoming solar energy. There is also the low-emissivity glass engineered to minimize heating and cooling costs, but as far as UVR is concerned, such glasses, without any distinctive anti-UV coating, behave similarly to clear glass where most UVRB is blocked but allows most UVRA to pass through. The best of protection comes from a class of glasses purposely formulated to block out between 95 to $99 \%$ of all incident UV radiation. An example is laminated glass, which is made of two layers of glass with a plastic layer in between. It is used in public buildings such as airports and museums and also for automobile windshields (Almutawa et al., 2013).

People these days spend long hours in cars, which generally have their front windshields made of laminated glass and therefore suppress all of UVRB and the vast majority of UVRA. The side and rear windows on the other hand are usually made from non-laminated glass and therefore allow much of UVRA (60-70\%) through. Tinting, however, reduces UVRA penetration to about 15-30\%.(Almutawa et al., 2013).In investigations carried out on UV exposure in cars, the findings were that the parts of the driver's or passengers' bodies closest to non-laminated windows exhibited the most exposure to UVR (Kimlin, Parisi, Carter, \& Turnbull, 2002; Moehrle, Soballa, \&Korn, 2003; Parisi\& Wong, 1998).

UVR is known to have some very useful applications in maintaining the quality of food and water (Warriner, 2011). Despite such beneficial uses, it also has some negative effects as its exposure initiates free radical oxidation and catalyzes other stages of the oxidation process in food. Lipid radicals, superoxide radicals (SOR) and $\mathrm{H}_{2} \mathrm{O}_{2}$ are formed due to UV exposure (Kolakowska, 2003). De-naturation of components such as proteins, enzymes, and amino acids (especially amino acids with aromatic compounds) in milk may occur with UVR, thereby bringing about textural changes (Choudhary \& Bandla, 2012).Furthermore, a slight change in the molecular structure of a nutrient can render it biologically ineffective, making vitamins such as vitamin A, B2 (riboflavin), B6, B12 and folic acid specifically vulnerable to degradation by UVR (Connor, 2004). UVR on food is known to deplete its antioxidants and causes it to bleach (Warriner, 2011). Lemon flavor, for instance, is composed of several light-sensitive components including terpene hydrocarbons and oxygen-containing compounds that degrade upon exposure to UV radiation. The degradation of such flavor and fragrance ingredients in foods lead to a diminished sensory profile and the formation of unpleasant qualities detectable when taste and smell are at low concentrations (Connor, 2004).

In most developing countries many buildings have sprang-up without the needed technical advice, and therefore one cannot guarantee the quality of materials used, including especially the glass being fixed as window-glass. 
Plastics have also become indispensable and have led to applications in which they have replaced glass in various applications. The different forms of plastic materials include perspex, transparent Linear Low Density Polyethylene (LLDPE) and Polyethylene Terephthalate (PET). Perspex, also known as Polymethyl methacrylate (PMMA), or acrylic glass, is an important synthetic thermoplastic material. It is a clear plastic often used as a shatter-proof replacement to glass, offers resistance to strong alkaline or acid solutions and stable to heat and light (Alshehry \& Ismail, 2008).

LLDPE plastic bags are mostly used for the storage of food-grains and water while plastic PET bottle containers are used for the storage of water, juices and beverages. The issue here is that such food items are frequently exposed to direct sunlight. Figure 3 is a composite picture in which the top two pictures show labels from two different water manufacturing companies with an unequivocal instruction not to expose the content to direct sun rays. The bottom two pictures show a contrary practice where the water in the LLDPE plastic bags and juices in PET bottle containers are exposed to direct sunlight. Figure 4 shows a transparent LLDPE material being used as a replacement for the back-glass of a car. This study was carried out in Cape Coast, the Central Region of Ghana, and provides a scientific study of such materials by determining their ability to block UVR as they are used for protection against the effect of the sun.

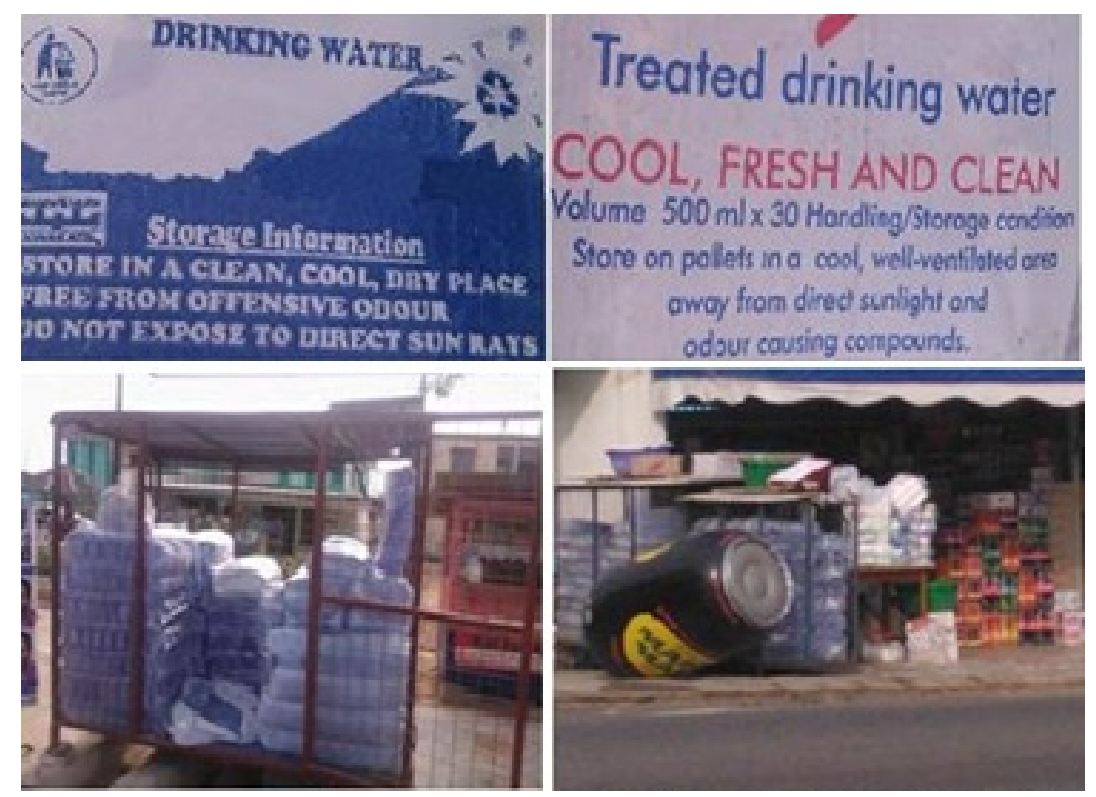

Figure 3. A composite picture depicting how LLDPE and PET materials are used in the storage of water and juices while being exposed to direct sunrays, and how transparent LLDPE materials are used as a replacement for glass in cars

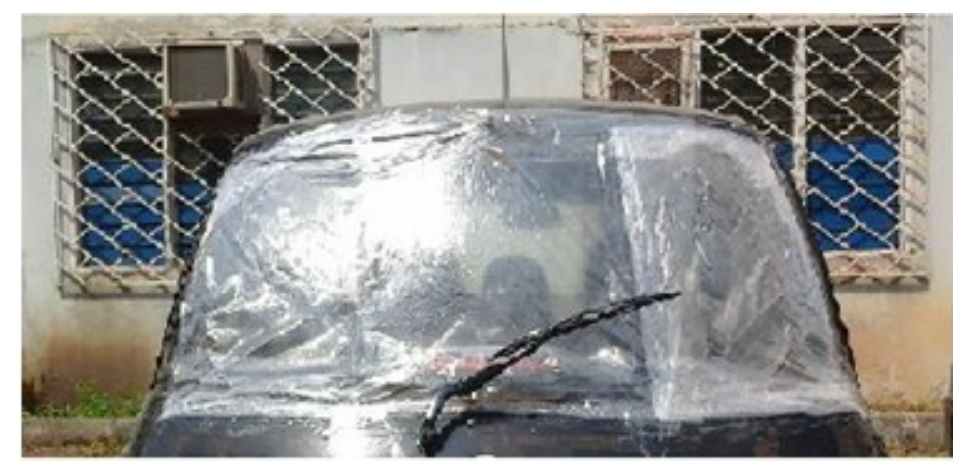

Figure 4. A picture showing a transparent LLDPE materials being used as a replacement for the back glass in a car 


\section{Materials Studied, Concept and Method}

\subsection{Materials Investigated}

The samples studied are listed in Table 1.

Table 1. Classification of samples investigated

\begin{tabular}{|c|c|}
\hline Samples & Types Studied \\
\hline Building-Window materials & Clear, Reflective, Tinted and Wired-Tinted Glasses \\
\hline Non-window materials & Quartz Glass, Perspex, Furniture-Glass \\
\hline Car Glasses & Windscreen (laminated), Side-Glass (non-laminated) \\
\hline Transparent Linear Low & Grain and Food Storage Bags \\
\hline Polyethylene (LLDPE) & Liquid Storage Bags (sachet bags) \\
\hline Polyethylene terephthalate (PET) & Plastic Bottle Containers for Liquid Storage \\
\hline
\end{tabular}

\subsubsection{Description of Materials Investigated}

\section{Building-Window glasses}

The clear window-glass studied is the standard transparent and nearly colorless window-glass used as louver-blades in buildings.

The Reflective glass is metallic-coated, reflects heat, and therefore reduces solar heat within an enclosure. For such glass, exterior views are unimpeded from the building interior while virtually eliminating the ability to see the interior of the building from the outside.

The Tinted glass contains color components purposely added to reduce unwanted solar heat transmission by absorbing some of the incoming solar energy.

The Wire-Tinted glass is a tinted glass with a wire-mesh inserted so as to make it shatter-resistant.

\section{Non-Window Materials}

The quartz glass consists of high-purity silica in amorphous form and has an extremely low coefficient of thermal expansion.

Perspex is a transparent thermoplastic used as a lightweight and shatter-proof substitute to glass.

The Furniture-glass is tempered-glass used in the furniture industry for the construction of kitchen cabinets and book-shelves.

\section{Car Glass}

The car-glasses investigated were of two types: laminated glass normally used for windscreen and non-laminated used as side-glass.

The building-window materials, non-building materials and car glasses investigated had dimension $20 \mathrm{~cm}$ by 20 $\mathrm{cm}$ and a thickness of $4 \mathrm{~mm}$.

\section{Linear Low Density Polyethylene (LLDPE)}

This is used for plastic bags and sheets and utilized in most traditional markets to store foods (especially grains) and water. In this study three different thicknesses $(0.15 \mathrm{~mm}, 0.30 \mathrm{~mm}$ and $0.45 \mathrm{~mm})$ of the type used to store food grains were studied and were represented as LLDPEA, LLDPEB and LLDPEC respectively. Sachet bags each with a thickness of $0.15 \mathrm{~mm}$ and used by 6 different purified-water producing companies were investigated.

These brands were 'Blue Crystal', 'AcquaFil', 'Cool Pak', 'Ahenpon', 'Kenro' and 'Standard Water', and were respectively represented as LLDPE1, LLDPE2, LLDPPE3, LLDPE4, LLDPE5 and LLDPE6.

\section{Polyethylene terephthalate (PET)}

This is a thermoplastic polymer resin used for the manufacture of plastic bottles as it is an excellent water and moisture barrier material. In this study plastic bottles each with a thickness of $0.35 \mathrm{~mm}$ and used by 4 different companies for the storage of water ('Voltic', 'Ice Pak' and 'BelAquah') and juice ('Coca Cola') were investigated. These were respectively represented as PET1, PET2, PET3 and PET4. 


\subsection{Light Reflectance, Absorbance and Transmittance}

Radiant flux incident on a surface or material will undergo reflection, absorption and transmission. Application of conservation of energy leads to the statement that the sum of the reflection, absorption and transmission of the incident flux is equal to unity. Mathematically, if the energy of the incident flux is normalized to 1 , then equation 1 (Palmer \& Grant, 2009) is valid:

$$
R_{r}+A_{r}+T_{r}=1(1)
$$

where $R_{r}, A_{r}$ and $T_{r}$ are the reflected, absorbed and transmitted radiations respectively. When radiation (light) enters a transparent material, part of its energy is absorbed and dissipated as heat, and therefore loses some of its intensity. The absorption of energy occurs selectively for different wavelengths and the light that gets transmitted will show only wavelengths that are not absorbed. If the intensity of the incident light for each wavelength is $I_{o}$, and the transmitted intensity is $I$, a plot of $I / I_{o}$ versus wavelength (transmittance) gives the absorption curve as shown in Figure 5. A yellow substance will have an absorption curve as represented by the solid curve while an opaque substance, which does not transmit any wavelengths, will have an absorption curve represented by the 'dash' red line. A normalized plot, when $I=I_{o}$ (for which ratio $I / I_{o}=1$ ), is represented by the 'dash' black line in the graph.

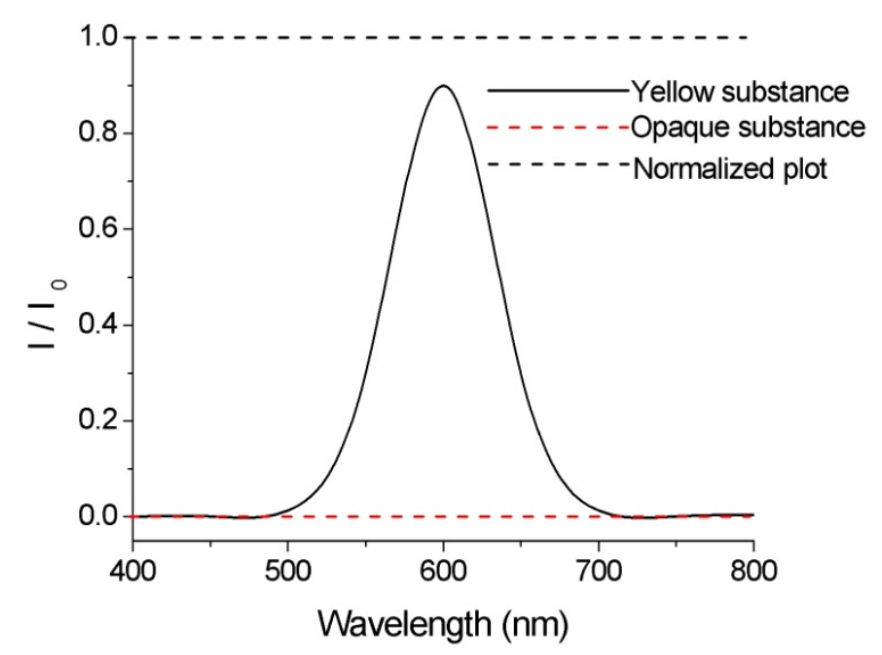

Figure 5. A plot of $I / I_{o}$ versus wavelength that gives the absorption curve for a material

\subsection{Method}

\subsubsection{Experimental Set-Up}

Figure 6 shows the diagram for the complete arrangement of the spectrometer used for data collection. 


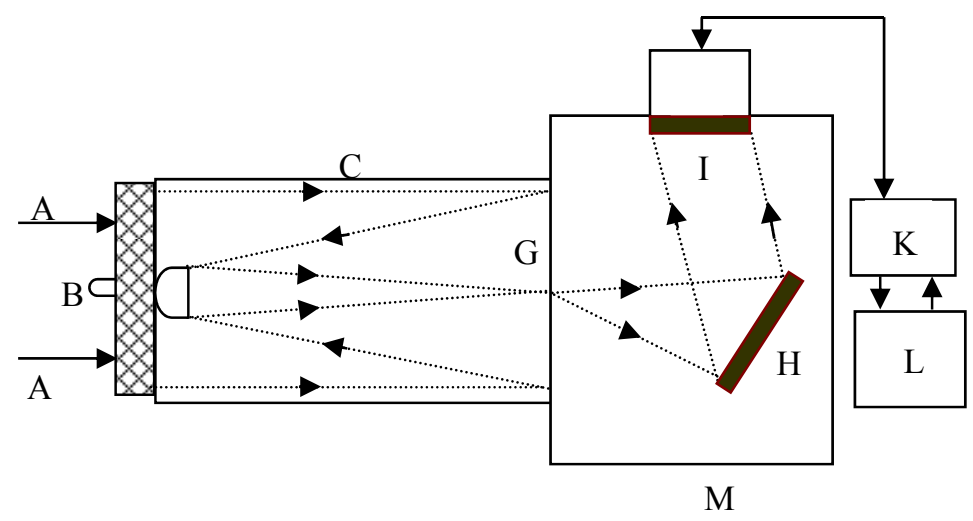

Figure 6. A complete arrangement of the spectrometer unit used

$A$ is the scattered solar radiation entering the spectrometer

$B$ is a Hg lamp

$C$ is a telescope

$G$ is an entrance slit

$H$ is a diffraction grating

$I$ is a detection system (ccd)

$K$ is the electronic module of the spectrometer unit (E-SU)

$L$ is a computer

$M$ forms the Monochromator

The receiving telescope ' $C$ ' focuses the incoming scattered solar radiation ' $A$ ' onto a fixed-precision type entrance slit ' $G$ ' with dimensions $0.1 \mathrm{~mm}$ wide by $2 \mathrm{~mm}$. The radiation is then focused onto the diffraction grating ' $H$ ' which spectrally disperses the radiation towards a detector ' $I$ ' made up of a CCD with 1024 pixels, all of which are illuminated during measurements. The grating ' $H$ ' is moved by a stepper motor and this enables the monochromator ' $M$ ' to analyze a spectral range of 2800-8000 $\AA$. The Hg lamp ' $B$ ' placed on top of the telescope is used for wavelength calibration. The entrance slit and detector positions were set to allow maximum amount of light passing through them to produce the brightest image. Inside the electronic module of the spectrometer unit ' $K$ ' is a Z80 microprocessor system that controls the operating mode of all the components of the spectrometer. This includes the reading of its 1024 output signals and their analog-to-digital conversion. A software operates the interface computer ' $L$ ' until the final 1024-pixel spectrum is received and stored. The receiving telescope, which is the entrance window to the spectrometer, has a diameter of $18 \mathrm{~cm}$. It is therefore completely covered when data is being collected as the samples studied had a dimension of $20 \mathrm{~cm}$ by $20 \mathrm{~cm}$.

\subsubsection{Calibration and Determination of the Linear Dispersion of Sensor}

The sensor took its measurements in pixels. It was therefore calibrated against a known standard to guarantee accuracy and validate its measurement technique against the wavelength scale that is mapped onto the CCD. This required measuring the spectral dispersion ( $\AA$ per pixel) of the spectrometer. The criterion used for this calibration was the discrete and fixed lines exhibited by Hg pencil-lamp. The standard wavelength positions of the Hg lamp were compared to the corresponding pixel positions observed using the spectrometer. To determine these pixel positions the entrance of the spectrometer unit was completely covered with an opaque material and the Hg lamp $B$ switched on. The spectrum of the Hg lamp was then captured within the UVB and UVA spectral intervals. FiguresFigure7a and 7bshow the standard detectable Hg lines in the UVB and UVA spectral regions respectively(Modified, LOT Oriel Technical Report, 2014) while the observable lines recorded in pixels within the same spectral regions using the sensor of the spectrometer are represented in Figures $7 \mathrm{c}$ and $7 \mathrm{~d}$ respectively.

From Figure 7it will be observed that parallels can be draw between the standard fixed lines exhibited by $\mathrm{Hg}$ lamp and the pixel positions recorded using the sensor of the spectrometer. Table 2 gives a tabular correspondence between these standard wavelengths and the pixel positions.

Using the values in Table 2, a plot of pixel position (x-axis) against wavelength (y-axis) gave a straight line. This 
is shown in Figure 8 for measurements in the UVB and UVA spectral regions. The slope gives a measure of the linear dispersion of the sensor.

The correlations established (in the UVB and UVA spectral regions) were used to determine the wavelength scale that was mapped onto the sensor, thereby converting pixels, as measured by the sensor of the spectrometer, to wavelength in $\AA$.
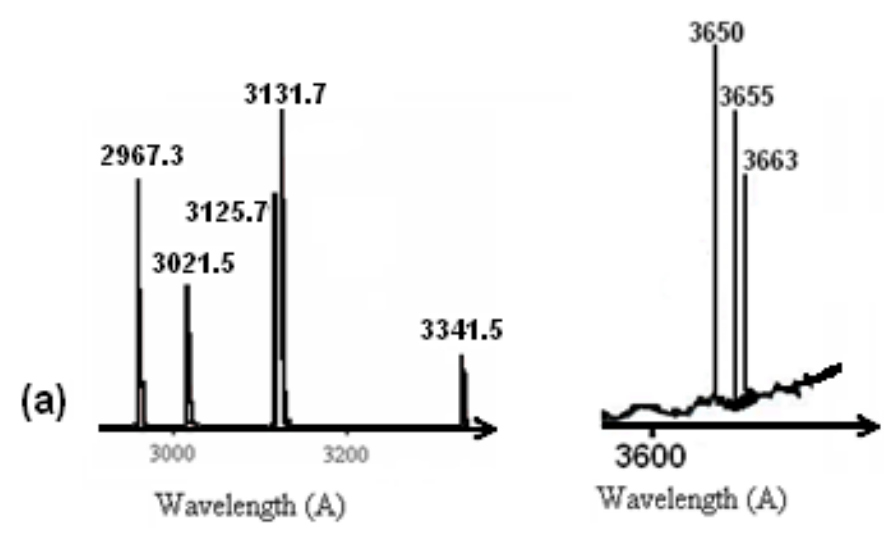

(b)
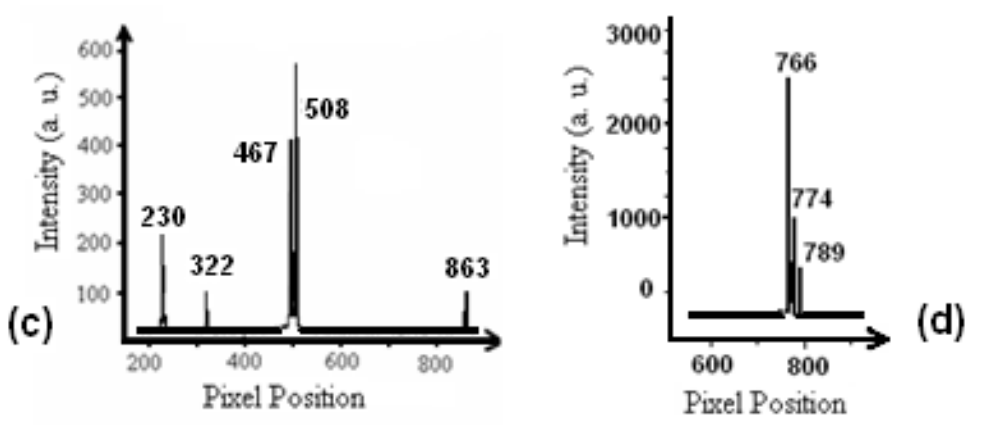

Figure 7. Graphs showing standard fine lines exhibited by Hg lamp(a) in the UVB and (b) UVA spectral regions (Modified, LOT Oriel Technical Report, 2014) and those observed in pixels for measurements in the (c) UVB and (d) UVA spectral regions

Table 2. Wavelength positions of fixed lines exhibited by $\mathrm{Hg}$ lamp and their corresponding pixel spots as observed using the sensor of the spectrometer for spectra taken in the UVB and UVA spectral regions

\begin{tabular}{cccc}
\hline \multicolumn{2}{c}{ UVB Spectral Region } & \multicolumn{2}{c}{ UVA Spectral Region } \\
Wavelength $(\AA)$ & Pixel Position & Wavelength $(\AA)$ & Pixel Position \\
\hline 2967 & 230 & 3650 & 766 \\
3022 & 322 & 3655 & 774 \\
3125 & 497 & 3663 & 789 \\
3132 & 508 & & \\
3342 & 863 & & \\
\hline
\end{tabular}



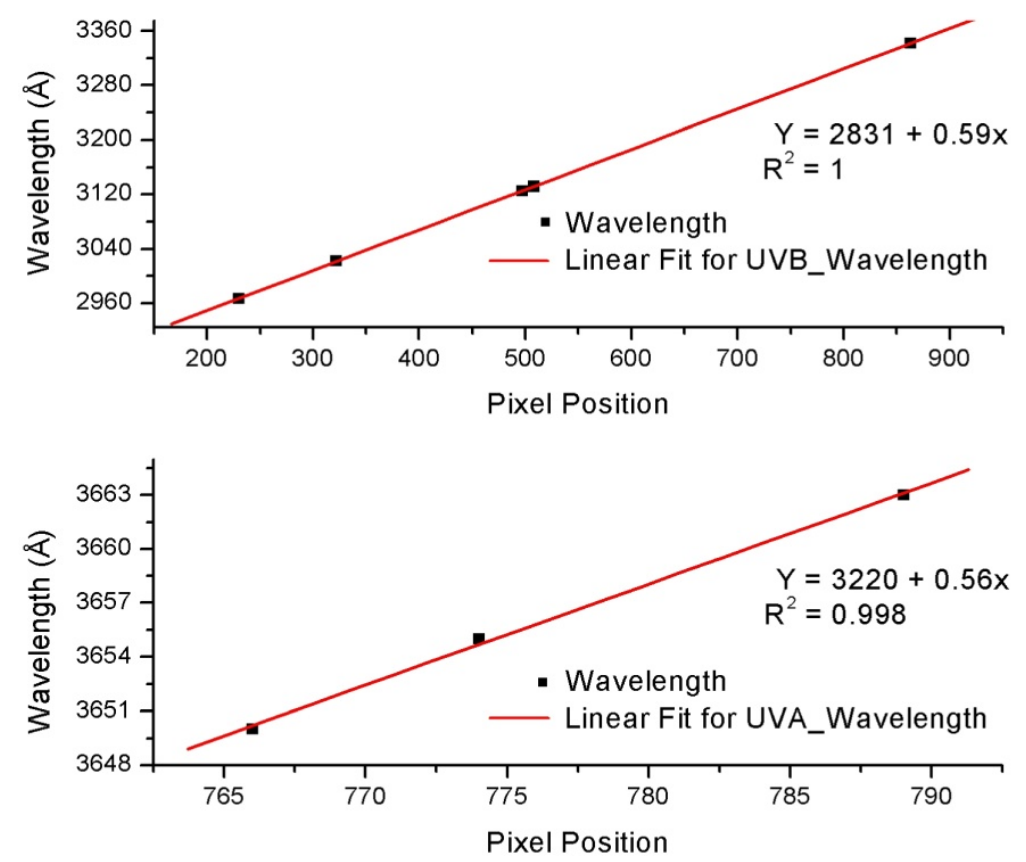

Figure 8. Graphs establishing relationship between wavelength and pixel-position pairs for measurements made in the UVB and UVA spectral regions

\subsubsection{Measurements Carried Out}

Two distinct measurements were carried out. Firstly, the intensity of the scattered solar radiation was measured by directly admitting the sunlight through the entrance window of the spectrometer. This gave the intensity of the 'raw' sun. The intensity of the scattered solar radiation was then again measured, this time, when the entrance window was completely covered with the material to be investigated. These two intensity measurements were carried out within the desired wavelength interval (UVB and UVA) by moving the diffraction grating with the help of the stepper motor.

\section{Results and Discussions}

Figures 9 to 12 show the spectra obtained for the different samples investigated in the UVB and UVA spectral regions. Figures 9 and 10 are composite graphs of intensity versus wavelength for wavelengths of light that are not absorbed (transmitted wavelengths) when sunlight is incident on the samples. In each of these graphs is a spectrum of the sun (labeled 'raw' sun) that can be compared with the spectra of the studied materials. Figures 11 and 12 represent the spectral transmittance graphs ( $I / I_{o}$ versus wavelength) of the materials. They give information on the amount of radiation at each wavelength transmitted through each sample as compared to the amount transmitted through air at that wavelength. For an opaque substance which does not permit the transmission of any wavelengths, $I=0$, and the ratio $I / I_{0}=0$. Such a graph will lie on the ' 0 ' mark and run parallel to the wavelength axis. It will only rise above the ' $O$ ' mark and show values at wavelengths that are transparent to the sample. The normalized values in these graphs (Figures 11 and 12) were obtained when $I=I_{0}$, therefore rendering the ratio $I / I_{0}=1$. A summary of the findings made from these graphs (Figures 9 to 12) that recap the extent of transparency for the materials investigated is given in Table 3. 

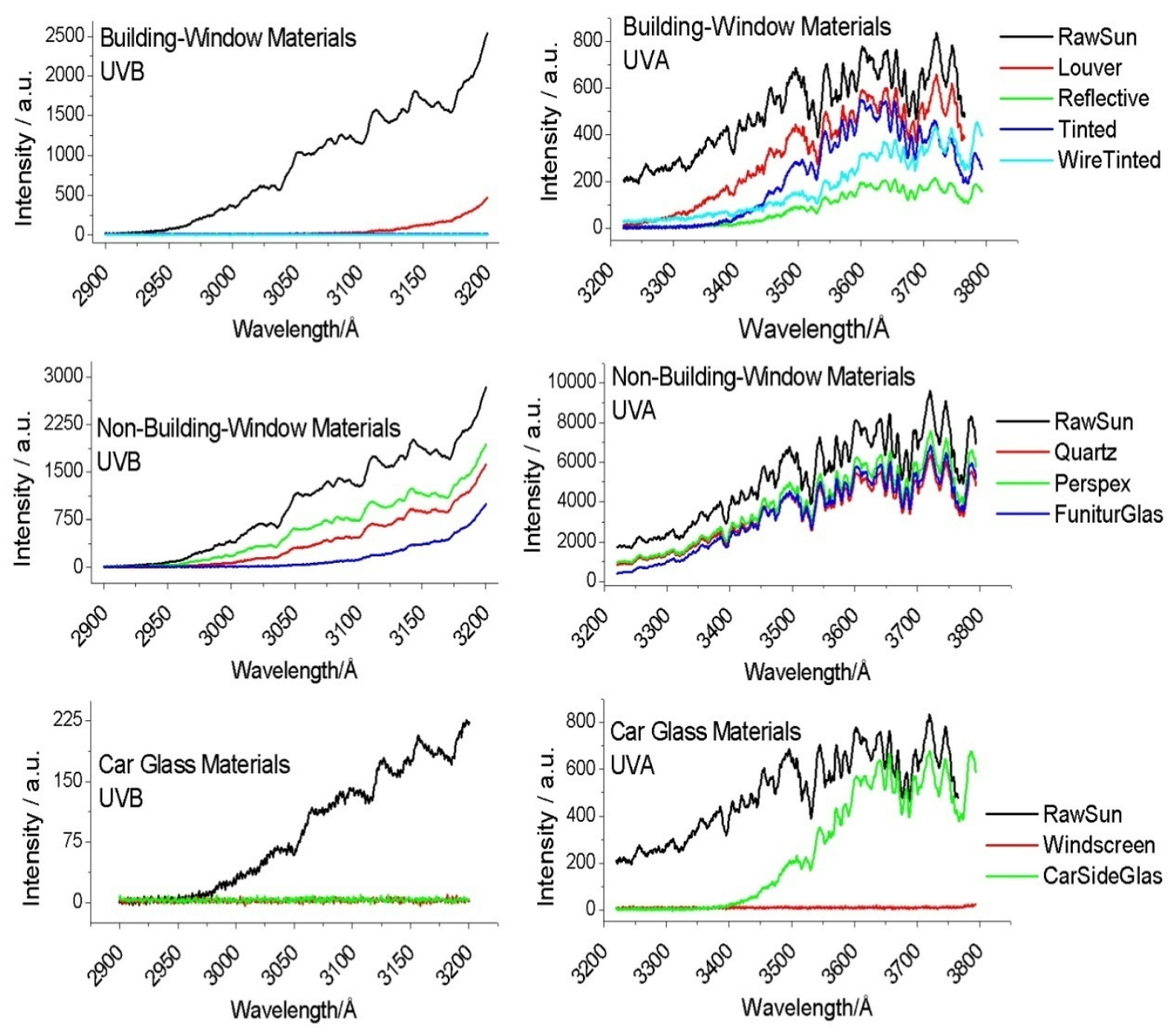

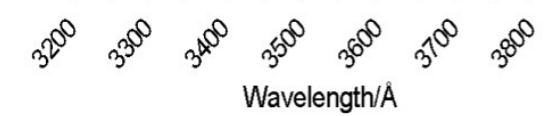

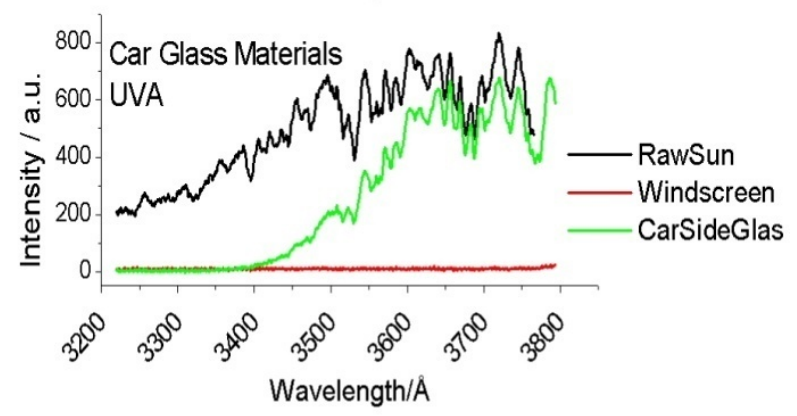

Figure 9. Composite graphs showing spectra of wavelengths that are not absorbed after sunlight is incident on thewindow and non-window materials, and car glasses for measurements in the UVB and UVA spectral regions 

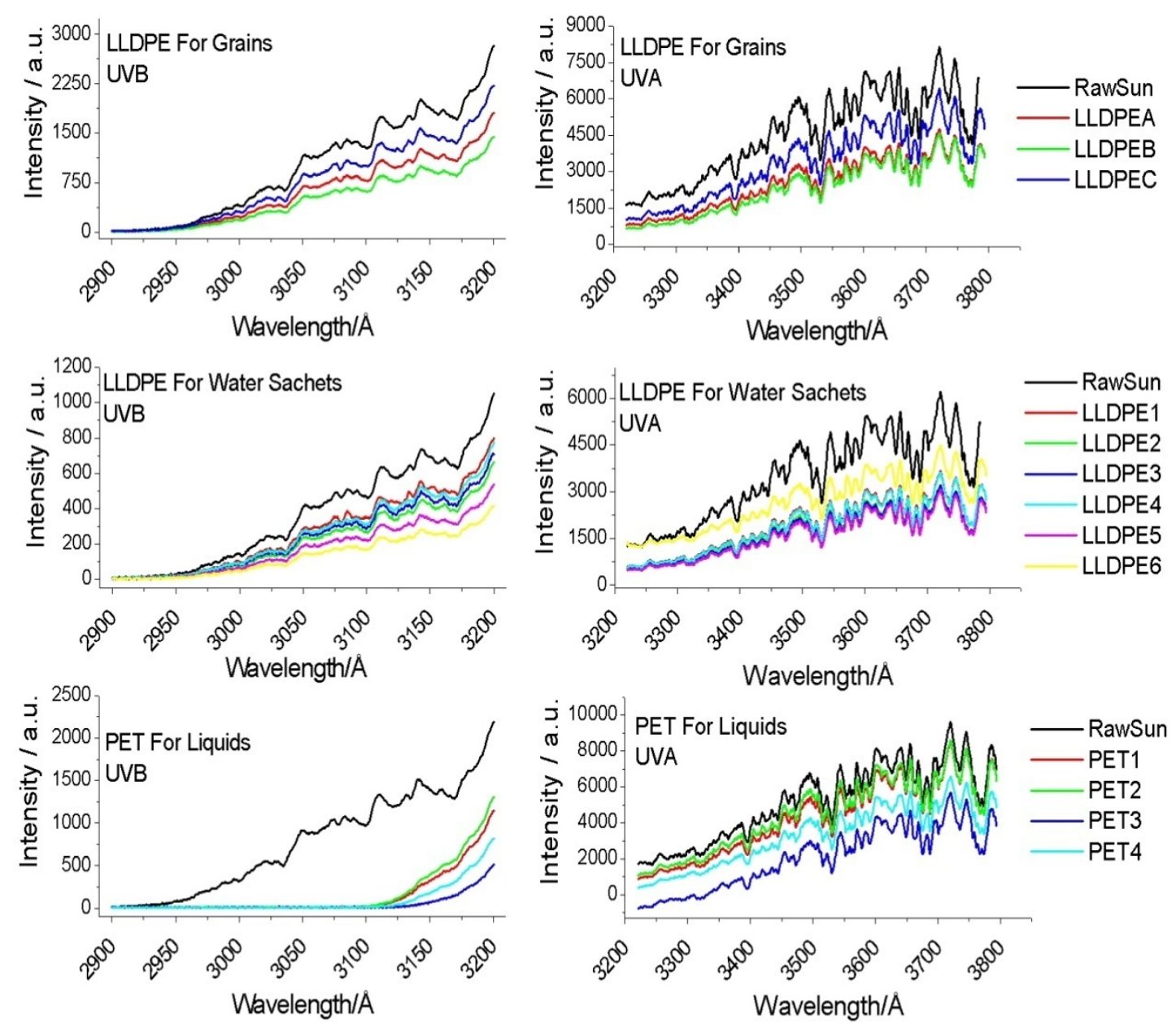

Figure 10. Composite graphs showing spectra of wavelengths that are not absorbed after sunlightis incident on the LLDPE and PET materials for measurements made in the UVB and UVA spectral regions 

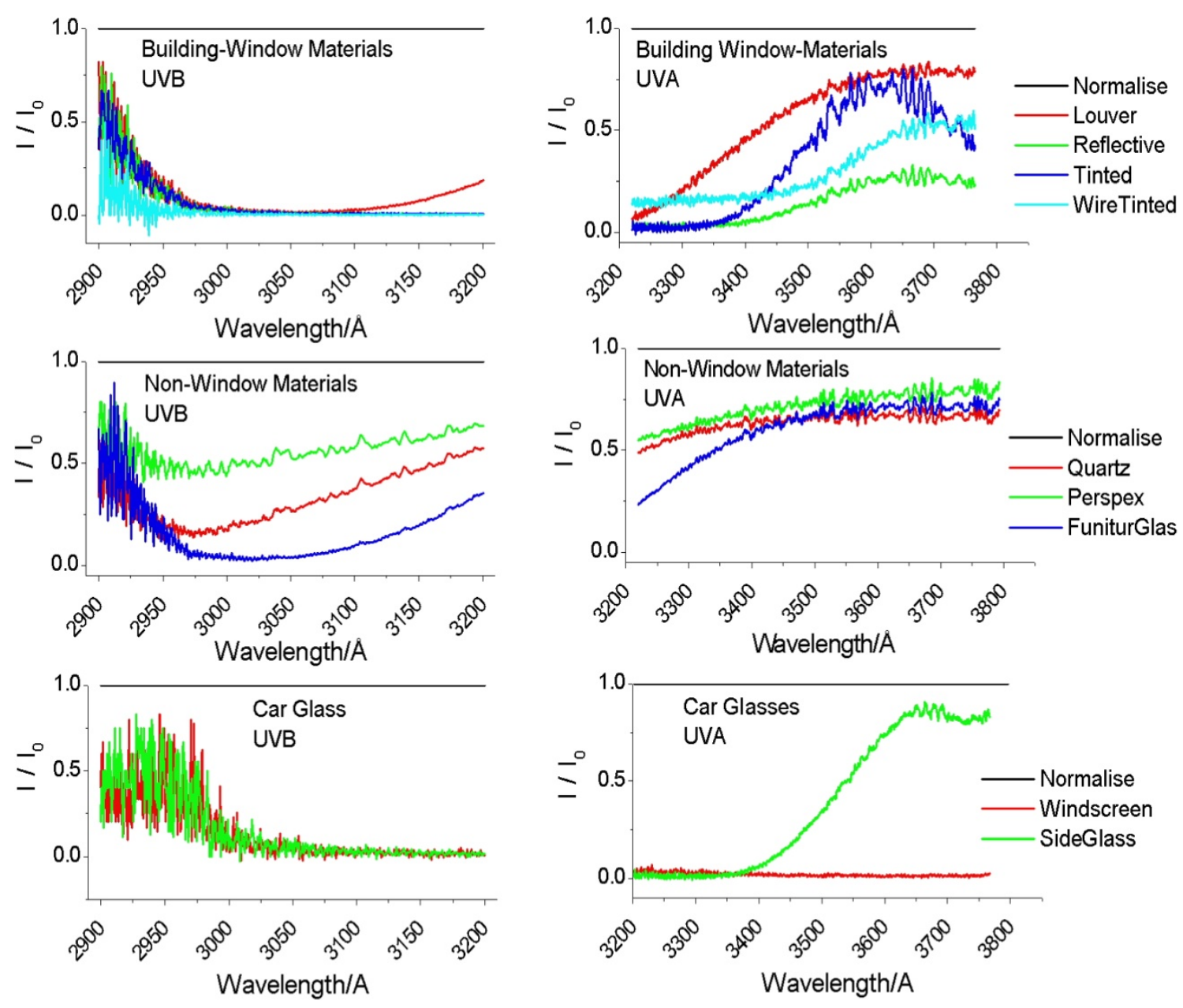

Figure 11. Composite graphs showing the spectral transmittance for the window andnon-window materials, and car glasses in the UVB and UVA spectral regions 

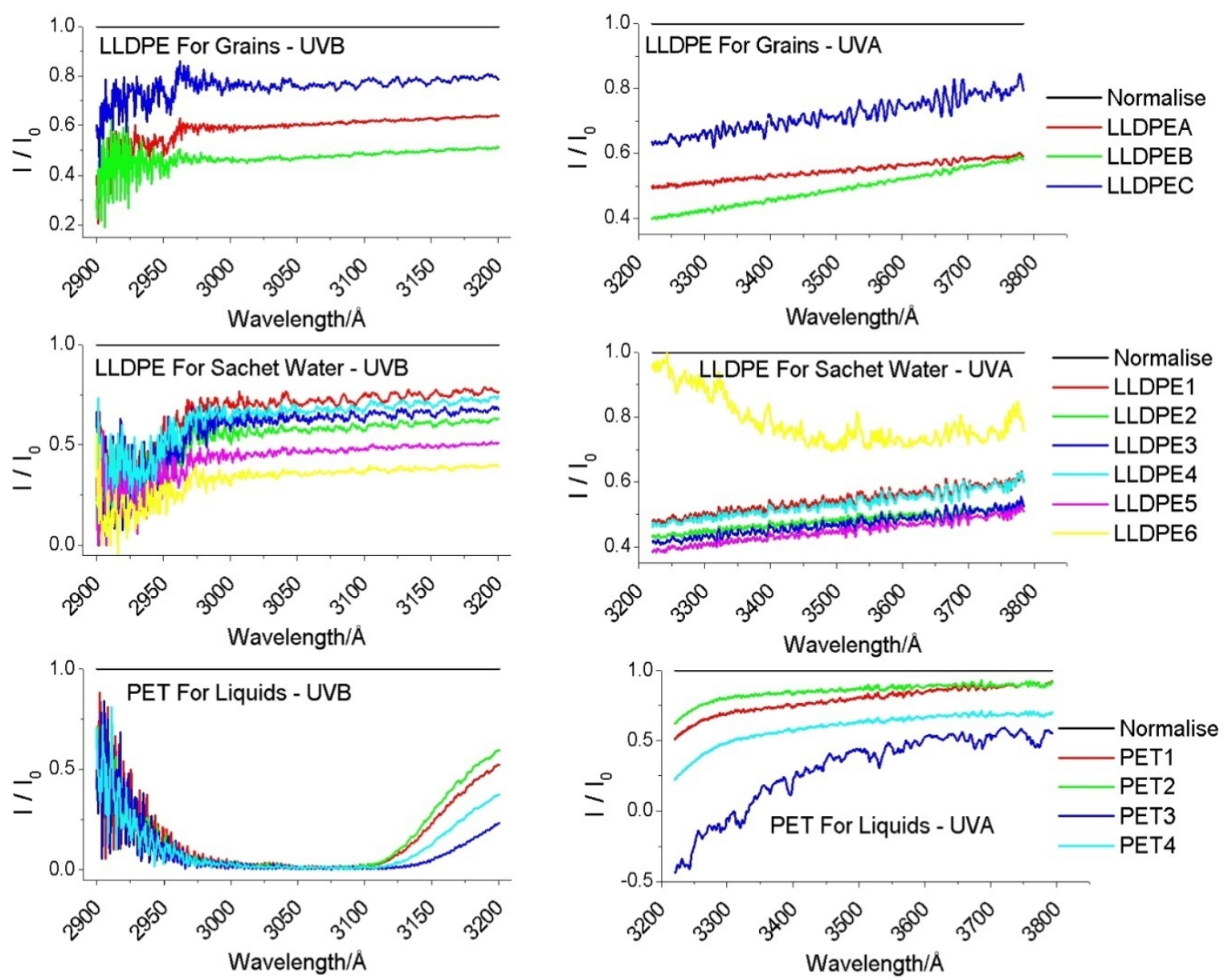

Figure 12. Composite graphs showing the spectral transmittance for the LDPE and PET materials in the UVB and UVA spectral regions 
Table 3. Summary of transparency of the materials studied

\begin{tabular}{|c|c|c|c|}
\hline \multicolumn{2}{|c|}{ Material Type } & UVB Transparency & UVA Transparency \\
\hline \multirow[t]{4}{*}{ Building-Window Glasses } & Louvre Blade & & \\
\hline & Reflective & Opaque & Transparent \\
\hline & Tinted & & \\
\hline & Wired/Tinted & & \\
\hline \multirow[t]{3}{*}{ Non-Window Materials } & Quartz & & \\
\hline & Perspex & Transparent & Transparent \\
\hline & Furniture Glass & & \\
\hline \multirow[t]{2}{*}{ Car Glasses } & Windscreen (Laminated) & Opaque & Opaque \\
\hline & Side Glass (Non-laminated) & & Transparent \\
\hline \multirow[t]{3}{*}{ LLDPE (Grain Storage) } & LLDPEA & & \\
\hline & LLDPEB & & \\
\hline & LLDPEC & & \\
\hline LLDPE (Water Sachets & LLDPE1 & & \\
\hline \multirow[t]{5}{*}{ Storage) } & LLDPE2 & Transparent & Transparent \\
\hline & LLDPE3 & & \\
\hline & LLDPE4 & & \\
\hline & LLDPE5 & & \\
\hline & LLDPE6 & & \\
\hline Bottles (Liquid & PET1 & & \\
\hline \multirow[t]{3}{*}{ Storage) } & PET2 & Opaque & Transparent \\
\hline & PET3 & & \\
\hline & PET4 & & \\
\hline
\end{tabular}

\section{The Building Window-glasses}

From Table 3 (obtained from an extraction from Figures 9 to 12), the Building Window-glasses investigated were opaque to UVB (though a relatively small level of transparency was observed between $305 \mathrm{~nm}$ and $320 \mathrm{~nm}$ for the louver blade) but transparent to UVA. These observations have been clearly depicted in Figures 9 and 11 . In Figure 9 it is observed that with the exception of the louver blade which showed small levels of radiations from $305 \mathrm{~nm}$, the rest of the samples did not register any radiations. This was accentuated in Figure 11 where the ratio $I / I_{0}=0$ for the samples, except for louver blade which registered values from $305 \mathrm{~nm}$, signifying some level of transparency from this wavelength. Within the UVA spectral region the extent of transparency depended on the make of the glass as the reflective and tinted glasses exhibited slight opaque characteristics between 320 $\mathrm{nm}$ and $335 \mathrm{~nm}$. These again can be clearly noted in Figures 9 and 11 using the same argument as explained for the UVB spectral region. These observations are in line with a previous study (Almutawa et al., 2013) which stated that standard window-glass filters out UVRB, and clear window glass allowed up to $72 \%$ of UV between $300 \mathrm{~nm}$ and $400 \mathrm{~nm}$ to pass through while reflective and tinted glasses have less transmission within the UVA spectral region in comparison to clear window glass.

\section{The Non-window glasses}

The non-window glass materials studied exhibited transparency in both UVB and UVA spectral regions as shown 
in Figures 9 and 11. From Figure 9, measurable intensity values (above 0) were recorded within the UVB spectral region (for the furniture glass it begins from $307.5 \mathrm{~nm}$ ) and UVA spectral regions. These findings were again confirmed in Figure 11. These findings (for the quartz Glass and perspex materials) conform to some Technical Report releases from Plexiglas and Praezisions Optics (Plexiglas, 2014; PraezisionsGlas \& Optik, 2014). The confirmation of the findings, especially for the perspex material, is particularly unsettling as it is mostly used as an alternative to glass (both as windscreen and side-glass) by many cars in developing countries. This means that photosensitive patients driving or traveling in such cars can experience exacerbations of their disease as they will be exposed to UVB and UVA from all directions.

From Figure 9, both the laminated and side glasses did not register any intensity in the UVB spectral region, and from Figure 11(within the same spectral region) the ratio $I / I_{0}$ was 0 . This signifies that the samples were opaque in this region. For the UVA spectral region, the laminated glass still did not register any intensity while the side glass showed some levels of radiation. These observations were highlighted in Figure 11 where the ratio $I / I_{0}$ for the laminated glass was 0 , but for the side glass, values greater than 0 were obtained. This makes the laminated glass opaque and the side glass transparent within the UVA spectral region. These findings were also consistent with conclusions drawn from earlier works (Almutawa et al., 2013; Kimlin et al., 2002; Moehrle et al., 2003; Parisi \& Wong, 1998).

Using the same argument as explained above, and making reference to Figures 10 and 12, it can be deduced that the LLDPE materials studied were all found to be transparent to both UVB and UVA. This finding is equally disturbing as it is often also used by some drivers as a substitute to either the windscreen or side glass of cars (as shown in Figure 1), and will therefore pose a problem for photosensitive patients. The PET plastic bottles were opaque to UVB (though a relatively small transparency was observed between $310 \mathrm{~nm}$ and $320 \mathrm{~nm}$ ) but transparent to UVA. This is indeed worrying as these materials are mainly used to store drinks and food in most developing countries (grains and water in LLDPE materials and drinks and beverages in PET bottles) and are normally exposed to the sun. Figures $3 \& 4$ show some of these activities, and therefore the knowledge that many vitamins are specifically vulnerable to degradation by UVR and can cause depletion in the antioxidants in our foods raises concern over storage in such materials and their exposure to the sun.

\section{Conclusion}

The sun's rays provide warmth and light that enhance our general well-being, but its overexposure is widely accepted as the underlying cause for some harmful effects on the skin and product-quality deterioration in the chemical composition of our foods. The proposal that one should shun the sun to avoid such negative effects has been proven not to be entirely valid, and therefore the need to investigate materials that principally offer resistance to UV penetration led to this study. This research was conducted in Cape Coast, in the Central Region of Ghana, on building-window and non-window materials, car glasses, Transparent Linear Low Density Polyethylene (LLDPE) and Polyethylene terephthalate (PET) materials. These are materials used in day-to-day activities to protect ourselves against the sun and also store our foods and drinks.

The pixel measurements of the spectrometer were converted to a wavelength scale by calibration using the fixed lines exhibited by a Hg pencil-lamb. Operating the spectrometer in the UVB and UVA spectral regions, the wavelengths of light that were not absorbed when sunlight was incident on the samples, and the amount of sunlight at each wavelength transmitted through each sample as compared to the amount transmitted through air were determined.

The findings were that the building-window glasses were opaque to UVB (though a relatively small transparency was observed between $310 \mathrm{~nm}$ and $320 \mathrm{~nm}$ for the louver blade) but transparent to UVA while the non-window glass materials were transparent in both UVB and UVA spectral regions. This means that the use of the perspex material (a non-window glass material) as an alternative to car-glass by commercial drivers should be strongly discouraged. Laminated glass used as windscreen in cars was confirmed to be opaque to both UVB and UVA, while the car side-glass was found to be opaque to UVB but transparent to UVA. These findings made on the Building-window glasses, non-window glasses and car glasses conform to findings made in the previous works of other authors.

Packaging of consumer foods and beverage products using LLDPE and PET materials have been extensively 
acknowledged due to their clarity which is akin to glass, wide flexibility in form, shatter resistance and efficient barrier for oxygen and scavengers. These packaging materials should guarantee a preservation of the integrity of their content during an entire shelf-life. This is why a study on such packaging materials is of relevance. The LLDPE materials were established to be transparent to both UVB and UVA, while PET plastic bottles were opaque to UVB (though a relatively small transparency was observed between $310 \mathrm{~nm}$ and $320 \mathrm{~nm}$ ) but transparent to UVA. With the findings that these materials do not provide a complete protection against UVR, one important assignment for material scientists may well be the addition of an effective UV filter to such materials. This will improve the stance of these materials as the leading packaging material of choice.

This study has brought to light the need to discourage the use of inappropriate materials during routine activities. It has also brought to fore the need to generally incorporate UV resistant materials into everyday substances like building window-materials, car-glasses, LLDPE and PET materials to ensure protection during their day-to-day use. When such UV resistant materials are engineered, there will be the need to verify their efficiencies to serve the intended purposes. This technique provides a scientific way of going about the verification.

It is hereby recommended that minimum standards in respect UVR shielding in the materials be set by regulatory authorities to protect the larger population from UVR risks. A certificate of testing that shows UVR shielding properties of the material before importation into developing countries maybe a good starting point towards standardization.

\section{Acknowledgement}

One of the authors, Samuel Sonko Sackey, will like to acknowledge funding from the Office of External Activities (OEA) of Abdus Salam ICTP. He specifically undertook part of this work with the support of the Program for Training and Research in Italian Laboratories (TRIL-ICTP), Trieste, Italy. The dedication of Prof. Daniele Treleani, Head of the program, is particularly recognized. By courtesy of this support, Sackey was trained in the use and operation of the specially developed spectrometer used for the data collection. The training was carried out at ISAC-CNR in Bologna, Italy, under the able leadership of Giorgio Giovanelli and his team.

\section{References}

Achwal, W. B. (1997). Sun protection properties of textile substrates. Colorage, 44(2),31-32.

Almahroos, M., \& Kurban, A. K. (2004).Ultraviolet carcinogenesis in non-melanoma skin cancer. Part I:incidencerates in relation to geographic locations and in migrant populations. Skinmed, 3, 29-35.http://dx.doi.org/10.1111/j.1540-9740.2004.02331.x

Almutawa, F., Vandal, R., Wang, S. Q., \& Lim, H. W. (2013).Current status of photo-protectionby windowglass,automobile glass, window films, and sunglasses. PhotodermatolPhotoimmunolPhotomed, 29(2), 65-72.http://dx.doi.org/10.1111/phpp.12022

Alshehry, S. D.,\& Ismail, I. M. I. (2008).PMMA degradation protection investigation using ultraviolet additive. Oriental Journal of Chemistry, 24(1), 35-42.

Choudhary, R., \& Bandla, S. (2012). International Journal of Food Science and Nutrition Engineering, 2(1), 12-15.http://dx.doi.org/10.5923/j.food.20120201.03

Connor, D. (2004).The Harmful Effects of UV Light Exposure.Technical Report of Milliken Chemicals. Retrieved from http://www.packaging-gateway.com/features/feature16

Cummings, S. R., Tripp, M. K.,\& Herrmann, N. B. (1997).Approaches to the prevention andcontrol of skin cancer.Cancer Metastasis Rev., 16, 309-327.http://dx.doi.org/10.1023/A:1005804328268

Diffey, B. L. (2002). What is light? PhotodermatolPhotoimmunolPhotomed., 18, 68-74.http://dx.doi.org/10.1034/j.1600-0781.2002.180203.x

Edlich, R. F., Winters, K. L., Cox, M. J., Becker, D. G., Horowitz, J. H.,\&Nichter L. S. (2004). Use of UV protective windows and window films to aid in the prevention of skin cancer. J. Long Term Eff. Med Implants., 14, 415-430.http://dx.doi.org/10.1615/JLongTermEffMedImplants.v14.i5.70

Kimlin, M. G., Parisi, A. V., Carter, B. D.,\& Turnbull D. (2002). Comparison of the solar spectral ultraviolet irradiance in motor vehicles with windows in an open and closed position. Int J. Biometeorol., 46, 150-156.http://dx.doi.org/10.1007/s00484-002-0131-5

Kolakowska, A. (2003). Lipid oxidation in food systems.In Chemical and functional properties of food lipids, 133-168. New York: CRC Press.

LOT Oriel Group Technical Report 2014, Light Sources for Calibration. Retrieved from 
http://www.lot-qd.com/files/downloads/lightsources/eu/LQ_Pen-Ray_Line_sources_for_wavelength_calibr ation_eu.pdf

Moehrle, M., Soballa, M.,\& Korn, M. (2003).UV exposure in cars. PhotodermatolPhotoimmunolPhotomed., 19, 175-181.http://dx.doi.org/10.1034/j.1600-0781.2003.00031.x

Newman, P. A., McGee, T.,\& Burris, J. (2002). An overview of the SOLVE/THESEO 2000 campaign. $J$. Geophys. Res., 107(D20), 8274.http://dx.doi.org/10.1029/2001JD001303

Palacin, F. (1997). Textile finish protects against ultraviolet radiation. Melliand Int., 3, 169-172.

Palmer, J. M.\& Grant, B. G. (2009).The Art of Radiometry. SPIE Press. Vol: PM 184.http://dx.doi.org/10.1117/3.798237

Parisi, A. V.,\& Wong, J. C. (1998).Quantitative evaluation of the personal erythemal ultraviolet exposure in a car.PhotodermatolPhotoimmunolPhotomed., 12-16.http://dx.doi.org/10.1111/j.1600-0781.1998.tb00003.x

Plexiglas UF-3 UF-4 and UF-5 sheets.Technical report 2014 from Plexiglas.com.

PraezisionsGlas \& Optik GmbH Technical Report, 2014.Retrieved from http://www.pgo-online.com/intl/katalog/quartz-glass.html

Reinert, G., Fuso, F., Hilfiker, R., \& Schmidt, E. (1997).UV-Properties of textile fabrics and their improvement.Text. Chem. Color., 29(12), 36-43.

Sliney, D. H. (2001).Photoprotection of the eye-UV radiation and sunglasses.J. PhotochemPhotobiol B., 64, 66-175.http://dx.doi.org/10.1016/S1011-1344(01)00229-9

Turnbull, D. J.,\&Parisi, A. V. (2003). Spectral UV in public shade settings.J. PhotochemPhotobiol B., 69, 13-19.http://dx.doi.org/10.1016/S1011-1344(02)00387-1

Wallace, J. M.,\& Hobbs, P. V. (1977).Atmospheric Science: An Introductory Survey. Academic Press, INC, Harcourt Brace Jovanovich Publishers.

Warriner, K. (2011). Presentations, 'Food Pathogen Interventions' Symposium in Seattle.Retrieved fromhttp://www.foodsafetynews.com/2011/05/food-pathogen-interventions-spotlight-on-uv/

Young, A. R. (2003). Are broad-spectrum sunscreens necessary for immune protection? J. Invest Dermatol., 121, 9-10.http://dx.doi.org/10.1046/j.1523-1747.2003.12507.x

Young, R. W. (1992). Sunlight and age-related eye disease. J. Nat Med Assoc., 84, 353-358.

\section{Copyrights}

Copyright for this article is retained by the author(s), with first publication rights granted to the journal.

This is an open-access article distributed under the terms and conditions of the Creative Commons Attribution license (http://creativecommons.org/licenses/by/3.0/). 